\title{
Ecology of subtropical hermit crabs in SW Madagascar: refuge-use and dynamic niche overlap
}

\author{
David K. A. Barnes ${ }^{1,2, *}$ \\ ${ }^{1}$ FRONTIER (Society for Environmental Exploration), 50-52 Rivington St., London EC2A 3QP, United Kingdom \\ ${ }^{2}$ Department of Zoology and Animal Ecology, University College Cork, Lee Maltings, Cork, Ireland
}

\begin{abstract}
Three sympatric species of semi-terrestrial hermit crabs (Coenobita cavipes, C. rugosus and C. pseudorugosus) occur on SW Madagascar shores on the edge of a semi-desert. They have similar resource requirements, some of which are restricted, yet their populations are very abundant. All 3 species seek refuges, the type and extent of which were assessed in 5 size classes for each of the species at 6 sites. Refuge-use, principally burrowing, was governed by a series of factors: tidal range, individual size (mass), species identity, site, shade. Shell architecture did not, however, directly influence refuge-use. An existing ordination technique (detrended correspondence analysis, DCA) was modified by inserting refuge identities as 'species terms' to interpret the structure underlying multidimensional niche space. The results show that variability in the refuge suite sought by hermit crabs serves to partition niche space both overall at the species level, and on a site-by-site basis for each species. On high spring tides, the extent of burrowing (a strategy common to all 3 species) was reduced, and a DCA of this data set showed niche compression at this tidal phase. Whilst biologically mediated niche shifts are a well-established concept, the changing of niche overlap described here clearly differs, as it is temporally dynamic and physically (tidally) driven. Inclusion of intertidal and subtidal hermit crabs at the study site into a data matrix showed that most species were separated ecologically by 4 niche dimensions: shore zone, habitat type, shell type and refugial behaviour. Niche complimentarity was clear, as species which were similar in 1 or more dimensions (such as C. rugosus and C. pseudorugosus) differed in other dimensions. Refuge-use of Coenobita spp. hermit crabs (and equivalent clustering behaviour of intertidal species) seems, therefore, to be multifunctional. The behaviour appears crucial to environment extremity avoidance, but may be equally important in resource management through water conservation and shell-, habitat- and shore-zone-partitioning. The results indicate that the SW Madagascar hermit crab assemblage is a speciose guild with (5D) niche complimentarity and temporally dynamic niche overlap.
\end{abstract}

KEY WORDS: Niche dynamism - Detrended correspondence analysis · DCA · Littoral burrowing · Coenobita $\cdot$ Africa

Resale or republication not permitted without written consent of the publisher

\section{INTRODUCTION}

Quantification of environmental extremity for organisms is not straightforward, since even what constitutes ecological severity is contentious. Upper and lower lethal temperatures, desiccation and chemical resistance and other tolerances can be determined in isolation, but do not give a whole environment picture.

*Present address: Life Science Division, British Antarctic Survey, High Cross, Madingley Road, Cambridge CB3 OET, United Kingdom. E-mail: dkab@bas.ac.uk
Polar seas are considered severe environments partly because of extreme temperatures, but they are also relatively constant, so it could be argued that they are accommodating for organisms (see Arntz et al. 1994). In contrast, tropical shores are thought of as benign, even compared to the temperate littoral (Pianka 1966), but fluctuations in many variables, not least temperature, can make them arguably as harsh for inhabiting organisms (McGuiness 1990). Some insects (Halobates sp.) occur as oceanic neuston, but cannot survive getting wet, and conversely some hermit crabs (Coenobita sp.) in Madagascar live on the fringe of a semi-desert 
but breathe through water (contained within their shells). Both Halobates spp. and Coenobita spp. are atypical, as most insects live on land not in the sea and most crustaceans live in the sea not on land. Yet both Halobates spp. and Coenobita spp. are also very successful. The sea skaters Halobates spp. and the hermit crabs Coenobita spp. are pan-tropical, highly numerous where they occur, and may ecologically dominate the fringe environments in which they occur (see Burggren \& McMahon 1988).

Most phyla arose in aquatic (marine) conditions and, typically, have stayed there, so they now have few terrestrial representatives (Barnes 1998). Chordates, chelicerates, and to a lesser extent 1 class of molluscs, have highly successfully invaded the land, whilst other taxa that have done so remain interstitial, and thus bathed in water. Despite the fact that hermit crabs have a heavy external (gastropod) shell, they have proved to be one of the more successful macrofaunal taxa on the terrestrial-marine interface and one of the most successful crustacean terrestrial invaders (with the exception of isopods). Their success may be due, in part, to the very presence of their shells (for water storage), but also to a number of developed behavioural traits such as clustering, migration and temporary refuge-seeking. The first of these, clustering, is a striking, common and multifunctional process of spatial organisation, which may facilitate shell exchange, minimise desiccation and separate species niche space (Gherardi et al. 1990, Gherardi \& Vannini 1993, Turra \& Leite 2000, Barnes \& Arnold 2001). Clustering is not such a common feature in semi-terrestrial species, and may purely reflect patchiness of food (Barnes 1997b) and available refugia (Barnes 1997a). Migrations are, in contrast, more typical of hermit crabs living above the intertidal fringe. Journeys vary from those of spectacular long (hundreds of metres) range (Vannini 1976) to beach-climbing journeys and from across nearhorizontal sand-flats to vertical tree-climbing (Barnes 1997a). Outward migrations enable individuals to be immersed in the sea and to find appropriate shells (Gherardi et al. 1990), food (Barnes 1997b) and probably of most importance water (Barnes 1997a). The return migrations may help individuals to avoid predators but crucially conserve water and temperature. This requires finding or creating a refuge. Although refugial options are limited, flexibility of strategy and the potential to use a suite of niches would enable their planktonic larvae to give rise to colonists on the widest variety of shores. Differential (interspecific) mechanisms of refugial behaviour would also serve to separate niches as many species of hermit crab frequently appear to overlap temporally, spatially and trophodynamically on shores. Interpreting the mechanisms of species coexistence and niche partitioning has proved a central task in understanding the dynamics of biodiversity. Hermit crabs, with clear and similar resource requirements, have been an obvious taxon for detailed niche analyses (Vance 1972, Gherardi \& Nardone 1997, Busato et al. 1998, Barnes \& de Grave 2000). Refugial behaviour has never been considered with respect to niche separation.

The wind-swept margins of the seasonally dry spinyforest represent a challenging habitat for essentially marine organisms living in the terrestrial sphere. Standing water and shade is scarce in this SW Madagascan semi-desert, whilst the temperatures and wind are high; thus, retaining moisture is clearly very important. The 5 species of macrocrustaceans that are abundant in the supralittoral or terrestrial belt above have conserved water in different ways. Of these 5, the only brachyuran crab, Cardisoma carnifex (Alexander), and the hermit crab Clibanarius longitarsus (de Haan) stay within the shade of mangroves and may be immersed at high water. The remaining (more terrestrialised) 3 are all coenobitid hermit crabs, and these must find or create refugia. The present study aimed at quantifying burrowing behaviour and differential use of refugia and their influences in SW Madagascan semi-terrestrial hermit crabs. Specifically, this study hypothesised: (1) refuge-use would be site-specific because of differential desiccation potential (such as shade and wind characteristics); (2) refuge-use would be species specific and thus segregate otherwise similar species; (3) scale, pattern and process of refuge-use would follow distinct tidal, circadian and environmental conditions; (4) shell architecture would influence success of refugial behaviour and thus choice of refugial behaviour.

\section{MATERIALS AND METHODS}

Study site and species. Refuge-seeking behavioural patterns were investigated in 3 sympatric species of semi-terrestrial hermit crabs (Coenobita cavipes Stimpson, C. rugosus H. Milne Edwards and C. pseudorugosus Nakasone) at Anakao, SW Madagascar (Fig. 1). The type and determinants of refuge creation were measured between June and September 2000 at 6 study sites: Anakao, Andavoka, Nosy Satrana North, Nosy Satrana South, Nosy Ve and Southern Point. Nosy Satrana and Nosy Ve are small inshore islands. All study sites are characterised by medium-grain sand beaches of similar slopes with large numbers of the bivalve Donax faba Gmelin burrowing at the lower shore levels (Lyle et al. unpubl. data). Behind the beaches is semi-desert scrub known as south-western seasonally dry spiny-forest. Southern Point has limited mangrove (Avicennia spp.) development but otherwise 

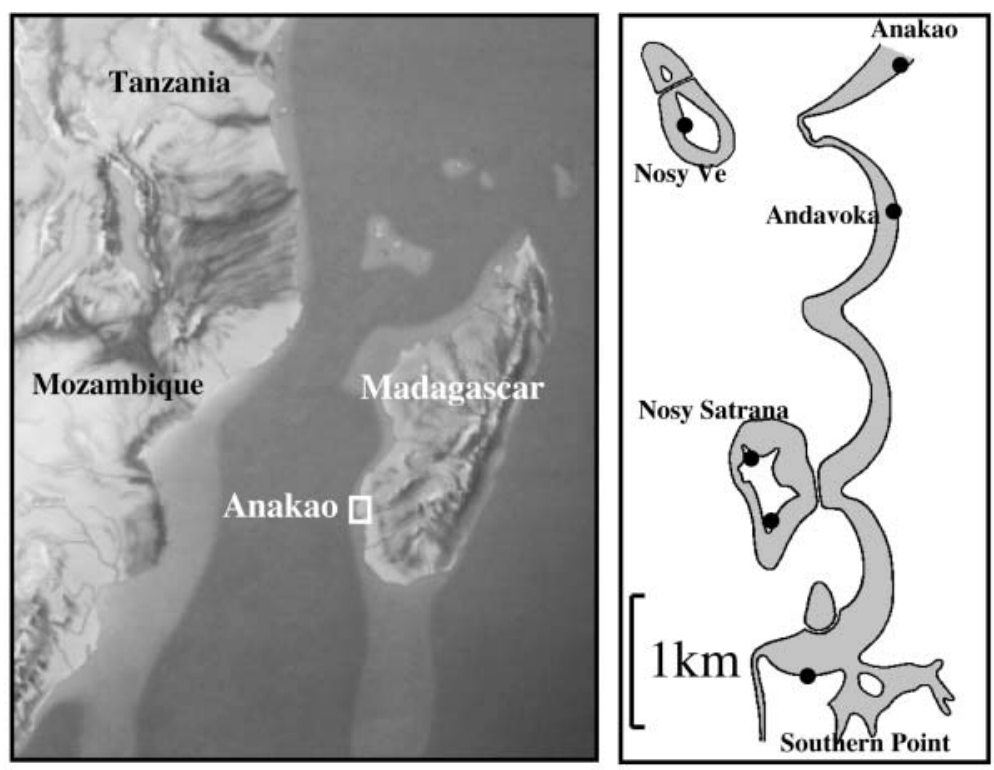

Fig. 1. Left: Locations of Madagascar and study region (Anakao) in the west Indian Ocean; right: detail of study region showing geographical relationship of sites and intertidal (shaded) beach areas

the biological characteristics differ imperceptibly between sites. The predominant wind direction is southsouth-westerly, making the Anakao and Southern Point sites wind-sheltered. Anthropogenic constructions (stone boulder above-surface graves) are present 3 and $5 \mathrm{~m}$ above mean high water spring tide level at Anakao and Nosy Satrana South respectively. Further (minor) details of the sites are given in Barnes \& Arnold (2001).

Five species of the genus Coenobita occur on Madagascar's shores (Reay \& Haig 1990), 3 of which are sympatric at the study site. Coenobita species are distinguishable on the basis of chelae morphology (to the naked eye: shape and colour). C. cavipes is common on East African shores, but rare outside mangroves in the Anakao region; amongst the 3 species studied it is easily recognisable by the lack of ridges on the top, outer margin of its chelae. C. rugosus is also a common and abundant species both at the study site and throughout the Indo-west Pacific realm. It is typically the most terrestrial of the East African Coenobita species, often occurring far inland (Vannini 1976). The rhythmicity of its burrowing (Vannini 1975) and tree-climbing (Barnes 1997a) has been studied in Somalia and Mozambique (respectively). The study site is the only known East African locality for the third species, C. pseudorugosus, which closely resembles C. rugosus (see Nakasone 1988).

Protocol. Observations were taken on refuge-use hourly at each site to establish timing of behaviour. The type of refugia being used by hermit crabs was surveyed between 11:00 and 13:00 $\mathrm{h}$ (midday, the peak time for refugial occupation) at the 6 study sites. At each site, 6 random replicate areas (welldefined quadrats, each $5 \times 2 \mathrm{~m}$ in size) were selected (to give $\mathrm{N}>20$ for each study species present), and refuge-use was recorded for all areas on the same date to eliminate pseudoreplication. Randomised selection of areas was ensured by generating numbers and using these as coordinates for centre points of the study quadrats and marking them on a map prior to arrival at the sites. The undersurface of bushes, boulders and algal debris were checked, tomb walls and tree roots inspected and all fresh burrows excavated. These refugia include virtually all hideaways described in the literature (de Wilde 1973, Vannini 1975, Burggren \& McMahon 1988, Gherardi et al. 1990, Barnes 1997a and pers. obs). The hermit crabs found in refuge were identified to species. This method was repeated on neap and spring tides and the results were arranged into a standard matrix which was subjected (untransformed) to ordination by detrended correspondence analysis (DCA) using Canoco4 software. Ordinations are used in preference for data with a gradient rather than divisive underlying structure. Ordinations (such as DCA) arrange data into 2-dimensional (or higher) space such that the points with close proximity correspond to similar suites of species or, as used here, refuges. Points that are distant therefore indicate dissimilarity in refuge composition. Although not a new technique for visualising underlying data structure (Hill \& Gauch 1980), it is still gaining familiarity with marine ecologists. Use of DCA, an advanced ordination technique, has 2 major gains over standard correspondence analysis, $\mathrm{CA}_{;}$it corrects for axis termini compression (relative to the axis middle), and the second axis has no systematic relation to the first axis. The use of DCA to examine niche space is, however, a recent expansion of applications of the technique (Barnes \& de Grave 2000). In the analyses reported here, only the first 2 axes were extracted as they jointly accounted for $>50 \%$ of the total variance explained and greater axes contributed little to further explanation of variance.

The number of individuals burrowing (or burrowed) in the study areas at the Andavoka site were counted each day for most of the period between mid-May and late-August 2000. These values were plotted against the magnitude of tidal range obtained from the literature. The burrow depth of each of the 3 study species was measured, using Vernier calipers, at the sites where they were present. Maximum and minimum burrow depth were recorded as the deepest and the 
shallowest (usually the apex of the gastropod shell carried) point reached by each individual respectively. Hermit crabs in burrows were removed, identified, and their shell architecture recorded as low-, medium- or high-spired (height to width ratios 1:1, 2:1 and $3+: 1$ respectively); they were classified as terrestrial or marine, separated from their shells and weighed using a Pesola spring balance and then allowed to return to their shells. Burrows were classed as shaded if they were shaded throughout the midday (11:00 to 13:00 h) period, and non-shaded only if they received no shade throughout the day. Data were collected on cloudless days to eliminate other provision of shade. To briefly examine the potential of burrowing to hinder desiccation, 20 Nerita spp. shells were placed on the surface of the sand from 11:00 to 13:00 h (during low water) and the time taken for them to dry was recorded. Incidence of hermit crab mortality was checked prior to and poststudy protocol but no mortality was found during the study period, so the individuals involved in the study are presumed not to have been seriously affected by exposure. Data were typically analysed, once tested for normality, using ANOVA or ANCOVA as appropriate.

\section{RESULTS}

\section{Refuge diversity and niche separation}

The 3 study species used 6 types of refugia: leaf litter under bushes, tree (mangrove) roots, algae deposited on the strandline, boulder undersurfaces, rock crevices

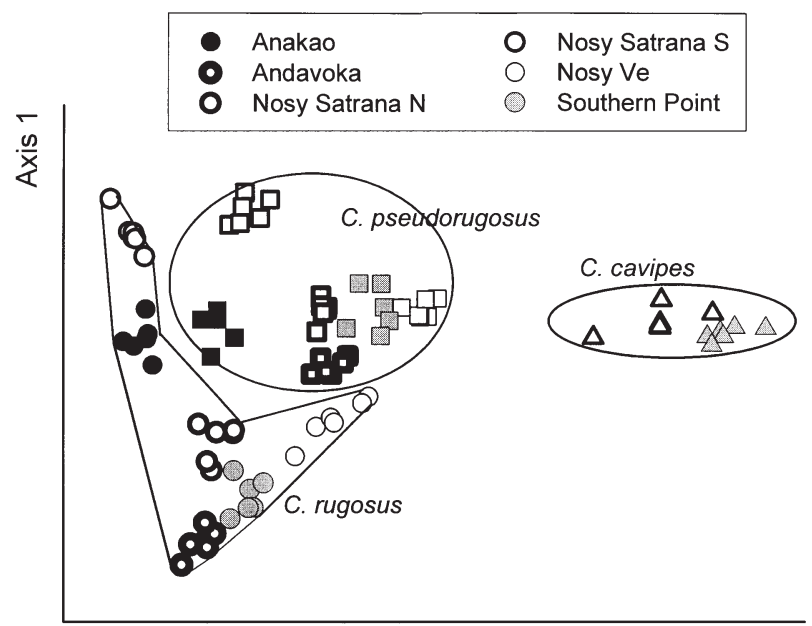

Axis 2

Fig. 2. Coenobita spp. Detrended correspondence analysis (DCA) of proportional use of refugia at neap tide as a function of site (Fig. 1) and species. Polygon lines drawn by hand to enclose species scores. Associated Eigenvalues and cumulative percentage variance explained by axes are shown in Table 1 and anthropogenic constructions (tombs). Across sites and replicate samples, all 6 refugia were used by Coenobita rugosus and C. pseudorugosus, whilst $C$. cavipes sheltered in just 3 ways. As hypothesised, refugial behaviour was highly site-specific: C. rugosus, for example, made much use of tombs at Anakao and Nosy Satrana (South) but crawled under bushes or burrowed elsewhere. For each species the suite of refugia used were so site-specific that there was virtually no overlap in suite characteristics between sites (Fig. 2). In addition, the position of each of the scores for each site for both C. rugosus and C. pseudorugosus (the species which occurred at all sites) were in the same relative positions within their species clusters. That is, Nosy Satrana scores were high on Axis 1, Andavoka scores low on Axis 1 and Nosy Ve scores high on Axis 2 for both species. There was, therefore, a similar response by $C$. rugosus and C. pseudorugosus in adaptation of refuge-use to site-specific characteristics. Of most note was the complete separation of the 3 species in terms of niche space (on the basis of refugial behaviour alone). The niches of $C$. rugosus and C. pseudorugosus were narrow whilst that of $C$. cavipes was more disparate (in multidimensional space, but represented in 2 dimensions by the DCA results). Not only were refugial suites (proportional usage of each refuge) of C. rugosus and C. pseudorugosus distinct for each site (enough for niche separation per se), but the area enclosed by all scores for each species irrespective of site were nonoverlapping (space enclosed by polygons in Fig. 2).

Refuge-use was not, however, static in time or space for any of the 3 species but varied along circadian and tidal cycles. Refugia were mostly sought at dawn and occupied until dusk, but at the more isolated site of Nosy Ve, shelter was mainly used over the midday period only. This temporal variability of refugia use did not measurably differ between species. Burrowing and the use of rock crevices showed strong variation with tidal range (Fig. 3, burrowing dynamics only shown).

Table 1. Coenobita spp. Eigenvalues and cumulative percent variance explained by axes of the detrended correspondence analyses (DCA) (Figs. $2 \& 4$ ). Analyses performed on numbers of hermit crabs using each type of refugia

\begin{tabular}{|lcccc|}
\hline Parameter & \multicolumn{5}{c|}{ Axes } \\
& 1 & 2 & 3 & \multicolumn{1}{c|}{4} \\
\hline DCA in Fig. 2 & & & & \\
$\quad$ Eigenvalues & 0.72 & 0.16 & 0.03 & 0.01 \\
\% variance explained & 55.9 & 12.7 & 2.2 & 0.9 \\
$\quad$ Cumulative \% variance & 55.9 & 68.6 & 70.8 & 71.7 \\
DCA in Fig. 4 & & & & \\
$\quad$ Eigenvalues & 0.32 & 0.08 & 0.02 & 0.01 \\
\% variance explained & 42.5 & 8.5 & 2.6 & 1.6 \\
Cumulative \% variance & 42.5 & 51.0 & 53.6 & 55.2 \\
\hline
\end{tabular}




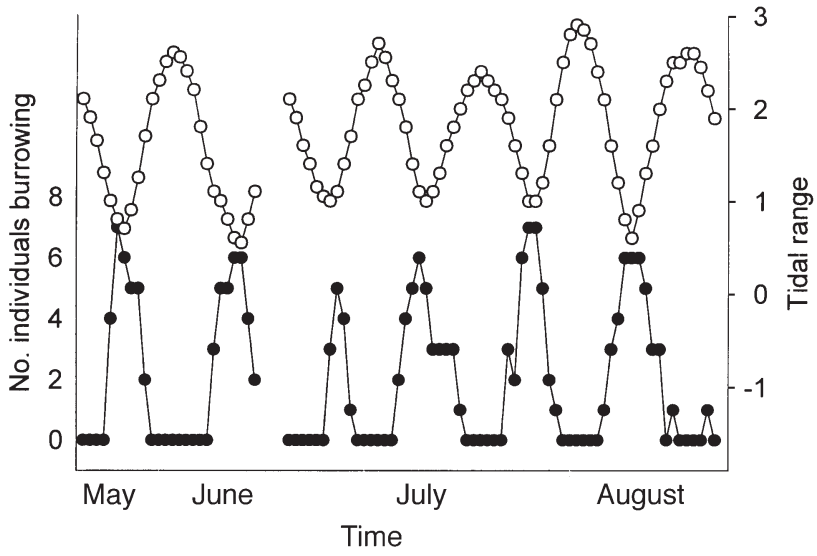

Fig. 3. Coenobita spp. Burrowing frequency as a function of tidal range and time of year. $(\bullet)$ Number of individuals burrowing; $(\mathrm{O})$ tidal range $(\mathrm{m})$

The number of individuals burrowing (per unit area) increased with decreasing tidal range, peaking on neap tides and decreasing to zero on spring tides. As each of the 3 species relied on burrowing as their refugia to a different extent, variability in tidal range had a differential interspecific influence. Coenobita cavipes burrowed most, then C. pseudorugosus and lastly $C$. rugosus. During spring tide diurnal periods the result, therefore, was compression of refugial suites of each species causing a reduction of niche space and separation (Fig. 4). At most sites the diversity of refugia used by C. rugosus and C. pseudorugosus was so similar (on spring tides) that site clusters for the 2 species overlapped (Fig. 4). The overall response of each species to different sites remained similar to that during neap

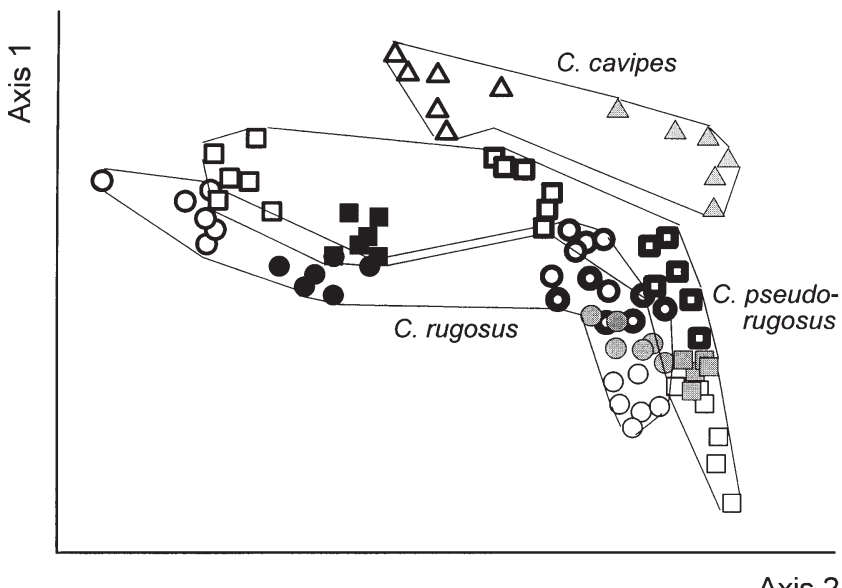

Fig. 4. Coenobita spp. Detrended correspondence analysis (DCA) of proportional use of refugia at spring tide as a function of site and species. Polygon lines and site designations as in Fig. 2. Size classes detailed in Fig. 5. Associated Eigenvalues and cumulative percentage variance explained by axes are shown in Table 1 tides (Nosy Satrana South and Nosy Ve clusters were most dissimilar, Southern Point and Andavoka clusters were highly similar, etc.). The distinctness of each site cluster, even within species, was much reduced. Even the refugial suites used by $C$. cavipes, which were highly dissimilar to those of the other Coenobita species on neap tides (Fig. 2), closely converged on $C$. pseudorugosus strategy. The refuge-use of hermit crabs on spring tides was, therefore, less species-specific and less site-specific. Nevertheless species-specific niche space was maintained at each site and overall, but inter-niche breadth between the 3 species was strongly compacted. Comparison of the DCAs (Figs. 2 \& 4) suggests that burrowing, a cross-species strategy, was important to niche creation and maintenance.

\section{Burrowing dynamics}

The most common element of refuge-use to the 3 study species was burrowing. In each case, burrow depth was significantly related to hermit crab individual mass (ANOVA, $\mathrm{df}=4, F>10.5, \mathrm{p}<0.001$ for each species). Although there was no significant difference between the burrow depths of Coenobita rugosus and C. pseudorugosus (ANCOVA [mass as covariate], $\mathrm{df}=1,1, F=3.2, \mathrm{p}=0.078)$, those of $C$. cavipes were significantly shallower than both the other Coenobita species (ANCOVA [mass as covariate], df $=1,1, F=$ $21.4, \mathrm{p}<0.001$ for pooled C. rugosus and C. pseudorugosus). Burrow depth was greatest in mid-sized individuals and shallowest in smallest individuals of all 3 study species (Fig. 5). Burrowing was also least preva-

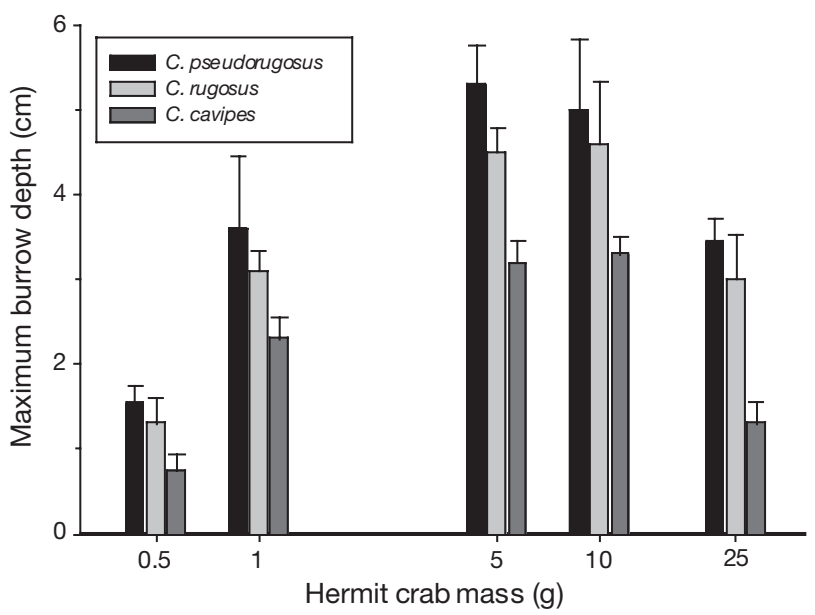

Fig. 5. Coenobita spp. Histogram of burrow depth as a function of species and hermit crab mass at Andavoka site. Data are means $\pm \mathrm{SE}(\mathrm{n}=50,50$ and 20 for Coenobita rugosus, C. pseudorugosus and C. cavipes respectively) for individual size classes (g mass) of $<1$ (shown as 0.5), 1-2.4 (1), 2.5-5 (5), $5.1-10(10)$ and $>10(25)$ 


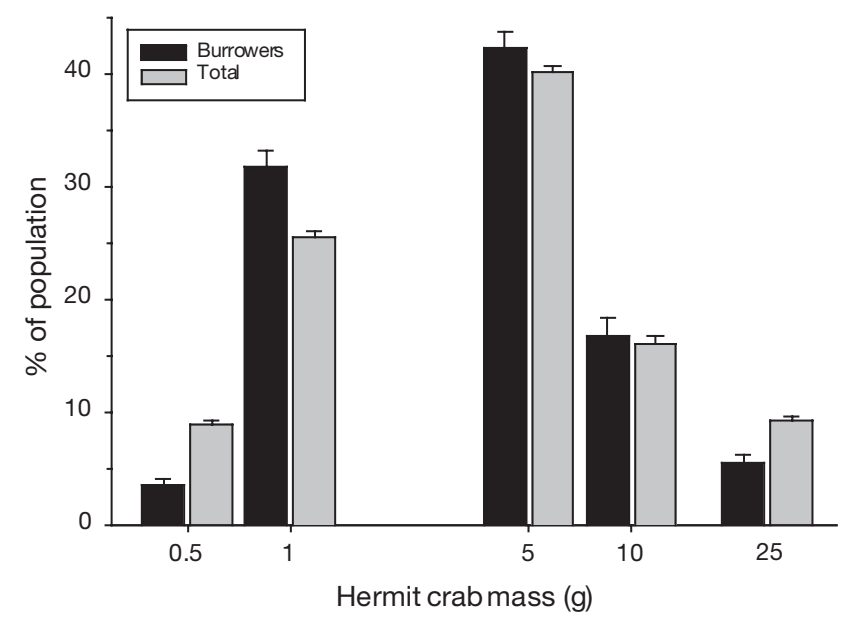

Fig. 6. Coenobita rugosus and C. pseudorugosus (combined data). Size-frequency histogram of total and burrowing populations at Andavoka site. Data are means + SE $(n=100)$ for size classes detailed in Fig. 5

lent in the smallest size class (Fig. 6). Individuals of $<1 \mathrm{~g}$ formed a significantly lower proportion of burrowing numbers than they did of the population as a whole $\left(\chi^{2}=57.7, \mathrm{p}<0.001, \mathrm{df}=28\right)$. The largest individuals were also under-represented as burrowers $\left(\chi^{2}=65.5, \mathrm{p}<0.001, \mathrm{df}=37\right)$ but the 1 to $2.5 \mathrm{~g}$ hermit crabs formed a greater proportion of burrowers $\left(\chi^{2}=\right.$ $33.8, \mathrm{p}<0.001, \mathrm{df}=36$ ). Hermit crabs of 2.5 to $10 \mathrm{~g}$ size ( $>50 \%$ population) formed the expected proportion of the burrowing population.

Hermit crab (maximum) burrow depth was significantly related to site (ANCOVA [mass as covariate], $\mathrm{df}=1,5, F=2.9, \mathrm{p}=0.04$ on pooled Coenobita rugosus

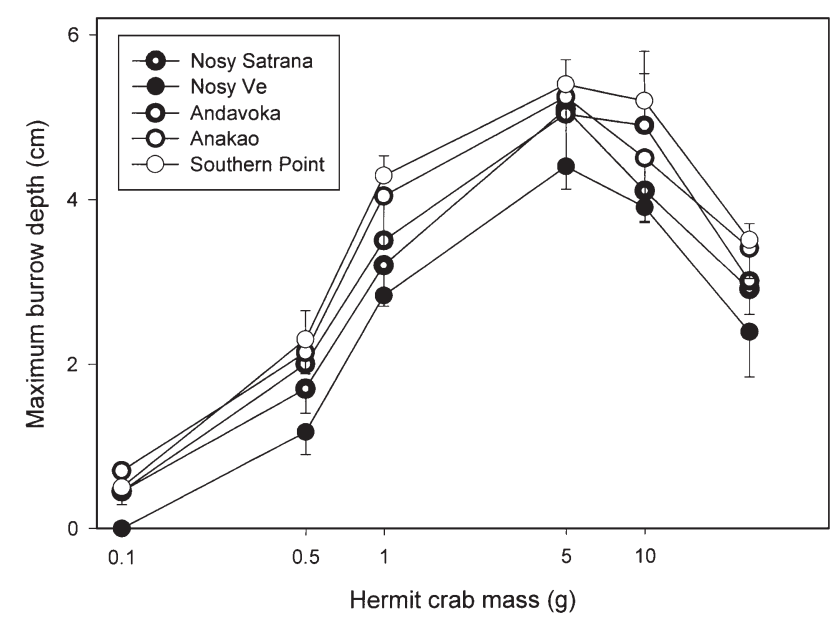

Fig. 7. Coenobita rugosus and C. pseudorugosus (combined data). Burrow depth as a function of site and individual mass. Data are means \pm SE ( $\mathrm{n}>10$ for each data point) for size classes detailed in Fig. 5 and C. pseudorugosus data). Those at Southern Point and Anakao (the 2 northerly facing and, therefore, wind-sheltered sites) were deepest whilst those at the most exposed site of Nosy Ve were shallowest (Fig. 7). The maximum extent of site variability was approximately $1 \mathrm{~cm}$, corresponding to $50 \%$ of burrow depth at $<1 \mathrm{~g}$ but only $20 \%$ of burrow depth for 2.5 to $5 \mathrm{~g}$ individuals. Minimum burrow depth showed a similar pattern, with site and individual mass essentially $1 \mathrm{~cm}$ lower on the $y$-axis. At 1 site, Southern Point, limited mangrove development provided shade. Shade had a significant and pronounced influence by reducing digging (ANCOVA [mass as covariate], df $=1,1, F>46$, $\mathrm{p}<0.001$ for both max. and min. burrow depths). Maximum burrow depth in the shade was about $40 \%$ of burrows exposed to full sunlight whilst minimum shaded burrow depth was only $10 \%$ of non-shaded depth (Fig. 8). Thus, non-shaded burrows at Southern Point rarely resulted in the (carried) shell being covered. Shell architecture did not, contrary to the stated hypothesis, have any significant influence on maxi-
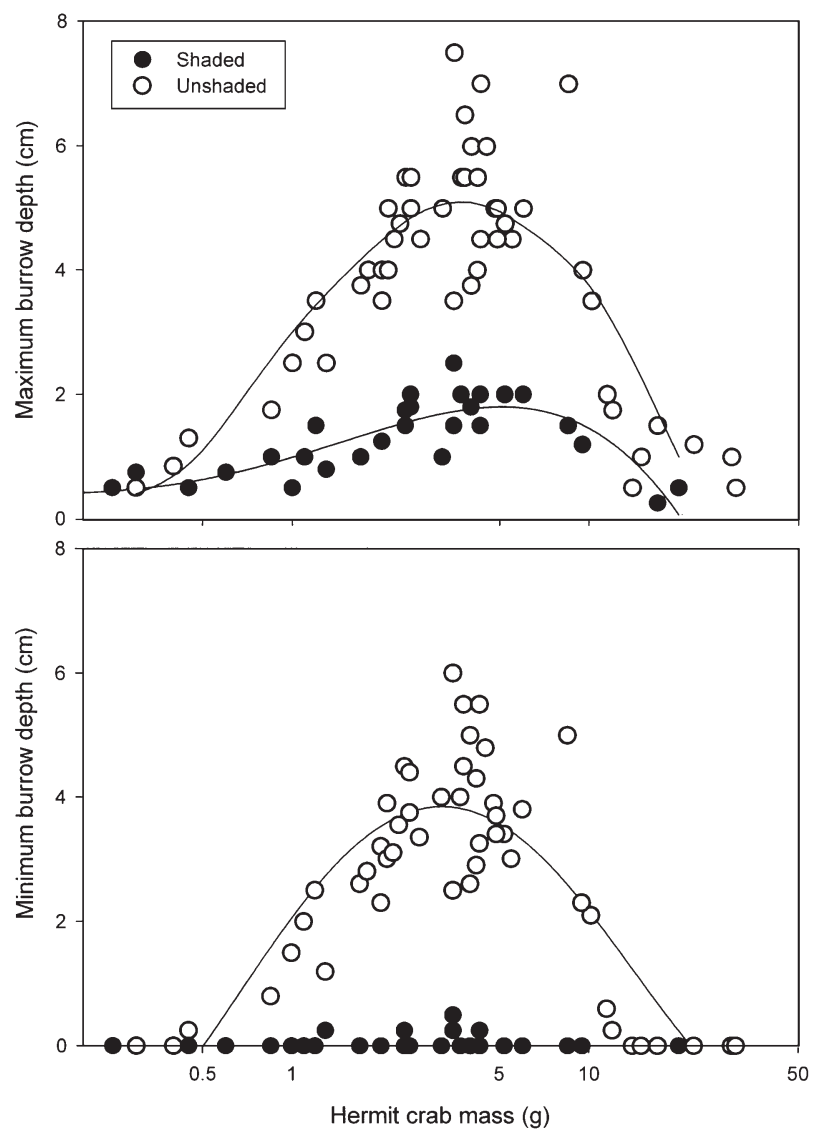

Fig. 8. Coenobita rugosus (top) and C. pseudorugosus (bottom). Burrow depth as a function of shade and individual mass at the Southern Point site. Fitted lines are significant third-order polynomial regressions, but serve only as trend lines to aid interpretation 
mum burrow depth (ANCOVA [mass as covariate], $\mathrm{df}=1,2, F=1.7, \mathrm{p}=0.18$. There was an incidental effect, however, as taller shell architecture reduced minimum burrow depth (ANCOVA [mass as covariate], $\mathrm{df}=1,2, F=4.5, \mathrm{p}=0.017)$. Although this was simply a consequence of shell length, rather than any influence of shell length on burrowing, the effect is potentially important as it means that tall shells were less likely to be covered (by sand). Both marine and terrestrial gastropod shells were used by C. rugosus and C. pseudorugosus. Not only was the architecture of these typically somewhat different, but terrestrial shells were much lighter; despite this, however, neither maximum nor minimum burrow depths were significantly different to those of crabs using marine gastropod shells (ANCOVA [mass as covariate], $\mathrm{df}=1,1$, $F=0.81, \mathrm{p}=0.37$ and $F=0.08, \mathrm{p}=0.78$ respectively). The 20 empty shells placed on the surface of the nonshaded sand all dried within the 11:00 to $13: 00 \mathrm{~h}$ period. Only 5 of the 20 shells dried at $1 \mathrm{~cm}$ depth, and none of the shells buried to $2 \mathrm{~cm}$ depth dried. In contrast, on shaded sand, 3 of the (20) empty shells on the surface still had traces of moisture when blotted and all buried shells retained moisture.

\section{DISCUSSION}

Refugial behaviour occurs widely in nature but differs dramatically with respect to timing, duration, function and microhabitat choice/creation. Burying and burrow excavation is one of the more ubiquitous methods (of refuge creation) and a process which serves medium-term dormancy such as hibernation or aestivation or short-term escape from predators or ecologically hostile conditions. Intertidal animals experience very different conditions at each tidal phase and can migrate to retain a constant medium (isophasic) or remain and seek refuge during their 'wrong phase' (isospatial); i.e. the wrong phase for an intertidal animal active when immersed is low water, and conversely the wrong phase for an intertidal animal active when emersed is high water. Hermit crabs are particularly adept at gaining refugia and have solved wrong phase protection in much the same way as other animals, by huddling together in clusters (e.g. Gherardi 1990), by burrowing (e.g. Rabaud 1936) or by using natural existing habitat characteristics (e.g. caves, trees). Supra-littoral hermit crabs, however, both migrate and seek refugia to optimise activity and avoid certain conditions of both circadian and tidal cycles (see Burggren \& McMahon 1988, Barnes 1997a). Refugial behaviour, such as burrowing, minimises diurnal hazards, such as desiccation and predation, whilst migration maximises space utilisation in a biphasic tidal environment. Bur- rowing, the most common across-study-species refugial technique, has been widely described in hermit crabs in terms of taxon diversity, burrow type and purpose (Rabaud 1936, Balss 1955, Rebach 1974, Vannini 1975). The burrows of the Coenobita species studied varied in extent from shallow scrapes, like those described for the intertidal species Pagurus ochotensis Brandt (MacGinite 1937) to complete individual coverage. Burrowing characteristics were influenced by tide (Fig. 3), individual mass and species identity (Figs. 5 \& 6) site (Fig. 7) and shade (Fig. 8), approximately in descending order (from multiple regression modelling: author's unpubl. data). Particle size and temperature, both known to influence burying behaviour (Rebach 1974), varied to only a negligible degree in the study on space and time (Lyle et al. unpubl. data). Shell architecture has also been found to influence refugial behaviour and choice (Barnes 1997a) but the present study found, surprisingly, no evidence for any direct influence on the extent of burrowing. Tall spired shells would, however, have the disadvantage of greater burrow depth required to cover them (exposed shells would warm up more than those buried). Conversely, tall spired shells should, if empty, hold more water. The explanations for the significant influences on burying behaviour are suggested to be relatively straightforward. Coenobitid hermit crabs typically prefer fresh water and generally avoid immersion (Burggren \& McMahon 1988); thus burrows are above, but not far above, the high-water mark. Spring tides cover most of the sand in the study area, making burrowing less attractive, so tides strongly influence both spatial and temporal aspects of the crabs' behaviour. The fact that individual mass greatly influenced prevalence and depth of burrowing probably reflects differential gain as well as biomechanical efficiency as a function of crab size. Interspecific differences would have been greater if intertidal species had been included in the analyses, as many of these form shallow scrapes, but this would have decreased the within-taxon (Coenobita) and shore-level (supra-littoral) resolution. Even so, no significant differences in burrow characteristics were found between C. rugosus and C. pseudorugosus. Site differences were probably due to wave exposure, as the deepest burrows were excavated at the most sheltered sites. The shallowest burrows at the most exposed site, Nosy Ve, would, in contrast to the sheltered beaches, frequently receive wave splash. Wave splash and therefore sand moisture must inrease with increasing exposure of the intertidal zone of sites, thereby increasingly constraining the need for burrow depth. Decreasing burrow depth with increasing shade seems, as with every other parameter, to be directly related to differential water loss. There seems to be little evidence that predation was of any notable influ- 
ence to refugial behaviour in the SW Madagascar study sites. Although predation of hermit crabs has been (infrequently) described (Reese 1969, Bertness 1981, Borjesson \& Szelistowski 1989), few animals attack or eat semi-terrestrial hermit crabs other than larger conspecifics (Barnes 1997b) or humans collecting bait (de Wilde 1973, Barnes 2001).

Aside from direct resource conservation, the study species in SW Madagascar may gain a further and perhaps critical advantage in the diversity of refuge types, i.e. resource-partitioning between co-existing species. Shells are often a limited resource to hermit crabs (see Kellogg 1976), and are so much so in SW Madagascar that Coenobita rugosus occasionally uses fossil shells (Barnes 2001). Yet, across shore zones and littoral habitats of SW Madagascar, many hermit crabs appear coincident in space and time using similar resources. The co-existence of species is considered to require distinct ecological 'separation'. Similar species can create such separation through differences in a number of ways including (1) distribution/range, (2) type of resource-use such as food or shells, (3) method of resource-use or other biological aspects. Considering these points in the same order: (1) Shore animals often exhibit striking zonation along littoral and substratum gradients. This is particularly noticeable in hermit crab genera (adults) and to a lesser extent at the specific level. The range of Coenobita species is higher up the shore than that of any other hermit crab, but the study species, particularly C. rugosus and C. pseudorugosus, differ little in habitat and zone occupation (Barnes 1997a). (2) Hermit crabs are typically scavenging omnivorous detritivores with little or no obvious partitioning of food resources (Hazlett 1981). The coenobitid species studied are, likewise, highly opportunistic consumers of detritus on the strandline and similar food (Barnes 1997b). Food is, therefore, highly unlikely to be significant in reducing niche overlap. However, most research has concentrated on differences in shell utilisation and/or preference, either by examining interference competition or, more rarely, exploitation competition (Reese 1969, Abrams 1978, Borjesson \& Szelistowski 1989, Gherardi 1990, Busato et al. 1998). Although Barnes \& de
Grave (2000) found that shell-use separated intertidal and supralittoral hermit crabs into a narrow but nonoverlapping mosaic of species niches, C. pseudorugosus was not present in northern Mozambique. Frequently shell-use overlap values are very high (see Hazlett 1981) and intertidal species in SW Madagascar seem to be largely separated by their differential clustering behaviour (Barnes \& Arnold 2001). (3) Variation in hermit crab mobility (Busato et al. 1998) or clustering behaviour (Barnes \& Arnold 2001) may separate species which are otherwise similar. It seems that the supra-littoral hermit crabs of the same region may also be segregated on the basis of their refugial behaviour.

Barnes \& de Grave (2000) modified ordination (canonical correlation analysis, CCA) use to compare niche space using the 'species' terms to code for gastropod shell types or 'resource species' using the actual hermit crab species (rather than habitats) as the samples. Further adaptation of an ordination technique (DCA), usually used for interpreting underlying data structure in species assemblages, can also be used with other characters instead of species. In the present study, refugia were inserted as a character instead of species. The results indicated that despite similarity of range, food and shells used, the species may be clearly separable by

Table 2. Main dimensions of resource-partitioning by 19 species of coastal hermit crabs in SW Madagascar. C.: Coenobita; Clib: Clibanarius; Ca: Calcinus; T: Trizopagurus; Di: Diogenes; P: Pagurus and Da: Dardanus. Horizontal lines: near total ecological separation; broken lines: partial separation (based on character where line is initiated). Intertidal and subtidal data from Barnes \& Arnold (2001). Table layout after Emmons (1980)

\begin{tabular}{|c|c|c|c|c|}
\hline Species & Shore zone & Habitat & Shell used & Refugia used \\
\hline C. rugosus & Supra & Sand scrub & Short/mid spire & Bush \\
\hline C. pseudorugosus & & & & Burrows \\
\hline C. cavipes & & Mangrove & Tall/mid spire & Burrows \\
\hline Clib ongitarsus & & & & Scrapes \\
\hline Clib striolatus & Upper/mid & Rock & Short/mid spire & Large clusters \\
\hline Ca laevimanus & & & Short spire & Mid clusters \\
\hline Ca latens & Lower & Coral reef & Short spire & Large clusters \\
\hline Clib virescens & & & & $\overline{\text { Small clusters }}$ \\
\hline Ca morgani & & & & Solo \\
\hline Clib eurysternus & & Rock & Tall spire/cone shells & Small clusters \\
\hline T. strigatus & & & Cone shells & Solo \\
\hline Di grandidieri & & Seagrass & Strombus shells & Small clusters \\
\hline P. hirtimanus & & & & Solo \\
\hline Di avarus & & Sand & Dogwhelk shells & Small clusters \\
\hline $\begin{array}{l}\text { Da guttatus } \\
\text { Da lagopodes }\end{array}$ & Subtidal & Coral reef & Cone shells & Solo \\
\hline Dardanus sp. & & & Trochus shells & Solo \\
\hline Da megistos & & Seagrass & Tulip/murex shells & Solo \\
\hline Da deformis & & & $\overline{\text { Moon shells }}$ & Solo \\
\hline
\end{tabular}


use of distinct suites of refugia (Figs. $2 \& 4$ ). Whilst overall niche distinctness appeared robust, spring tides caused a tight increase in niche overlap (Fig. 4) through reduction in burrowing. Change in niches or shifts has been a well-established concept since Connell's (1961) study, although in Connell's study, the compression of zones occupied by barnacles was mediated by a biological process (interference competition). Reduction in niche space and overlap in the present study clearly differs, as it is temporally much more dynamic and is governed by a physical process - tidal cycles. Data collected from the present study in combination with that on clustering in hermit crabs at the same site (Barnes \& Arnold 2001) enabled construction of a table (Table 2) detailing the preferences of each species. Within the guild of hermit crabs in SW Madagascar, niche differentiation certainly seems to be multidimensional and does to some extent show niche complimentarity (Emmons 1980). Species which are similar in one dimension, such as Coenobita rugosus and C. pseudorugosus (both supra-littoral, sand-scrub and short-spire shell users) differ in another dimension, refugial behaviour in this example. As with Emmons' (1980) study, most species were separated ecologically by 4 niche dimensions (in SW Madagascar these were shore zone, habitat type, shell type and refuge-use: Table 2), although results of the present study also demonstrate that burrowing dynamics represents a fifth dimension on which species could also be separated. So hermit crabs living within the same shore zone demonstrate either different habitat preference, shell choice or refuge-use/social structure. Several of the other possible niche dimensions (e.g. body size, migrations) did not seem to differ within zones (author's unpubl. data), however, probably because of physiological constraints. Refuge-use by these hermit crabs may therefore serve to avoid harsh environmental conditions, and to conserve one resource (water) whilst partitioning others (shells, habitats and shore zones).

Acknowledgements. The author wishes to thank all the scientific staff, logistic staff and volunteer research assistants of the Darwin/Frontier Madagascar Marine Research Programme, particularly those of Phase III. This is a collaborative venture between the Society for Environmental Exploration (SEE) in the UK and the Institut Halieutique et des Sciences Marines (Universite de Toliara). I am very grateful to the highly constructive and careful reviewing by Dr. A. Turra and 2 anonymous referees. In addition I am grateful to Rod Arnold for aid with data collection at Anakao, and finally I would also like to thank Jo and Finn Barnes for their company, perseverance and support.

\section{LITERATURE CITED}

Abrams P (1978) Shell selection and utilisation in a terrestrial hermit crab, Coenobita compressus (M. Milne Edwards). Oecologia 34:239-253
Arntz WE, Brey T, Gallardo VA (1994) Antarctic zoobenthos. Oceanogr Mar Biol Annu Rev 32:251-303

Balss H (1955) Ökologie, Decapoda. Bronn's Kl Ordn Tierreichs 5:1285-1476

Barnes DKA (1997a) The ecology of tropical hermit crabs at Quirimba Island, Mozambique: vertical migration (tree climbing). Mar Ecol Prog Ser 158:233-240

Barnes DKA (1997b) The ecology of tropical hermit crabs at Quirimba Island, Mozambique: a novel and important food supply. Mar Ecol Prog Ser 161:299-302

Barnes DKA (2001) Ancient homes for hard-up hermit crabs. Nature 412:785-786

Barnes DKA, Arnold RJ (2001) Ecology of subtropical hermit crabs in SW Madagascar: cluster structure and function. Mar Biol 139:463-474

Barnes DKA, de Grave S (2000) Ecology of tropical hermit crabs at Quirimba Island, Mozambique: niche width and resource allocation. Mar Ecol Prog Ser 206:171-179

Barnes RSK (1998) The diversity of living organisms. Blackwell Science, Oxford

Bertness MD (1981) Predation, physical stress, and the organisation of a tropical hermit crab community. Ecology 62: 411-425

Borjesson DL, Szelistowski WA (1989) Shell selection, utilization and predation in the hermit crab Clibanarius panamensis Stimpson in a tropical mangrove estuary. J Exp Mar Biol Ecol 133:213-228

Burggren WW, McMahon BR (1988) Biology of the land crabs. Cambridge University Press, Cambridge

Busato P, Benvenuto C, Gherardi F (1998) Competitive dynamics of a Mediterranean hermit crab assemblage: the role of interference and exploitative competition for shells. J Nat Hist 32:1447-1451

Connell J (1961) The influence of interspecific competition and other factors on the distribution of the barnacle Chthamalus stellatus. Ecology 42:710-723

de Wilde PAWJ (1973) On the ecology of Coenobita clypeatus in Curaçao. Stud Fauna Curaçao 44:1-138

Emmons LH (1980) Ecology and resource partitioning among nine species of African rain forest squirrels. Ecol Monogr $50: 31-54$

Gherardi F (1990) Competition and coexistence in two Mediterranean hermit crabs, Calcinus ornatus (Roux) and Clibanarius erythropus (Latreille) (Decapoda, Anomura). J Exp Mar Biol Ecol 143:221-238

Gherardi F, Nardone F (1997) The question of coexistence in hermit crab population ecology of a tropical intertidal assemblage. Crustaceana 70:608-629

Gherardi F, Vannini M (1993) Hermit crabs in a mangrove swamp: proximate and ultimate factors in the clustering of Clibanarius laevimanus. J Exp Mar Biol Ecol 168:167-187

Gherardi F, Micheli F, Vannini M (1990) Movement patterns and dispersal of the hermit crab Clibanarius longitarsus in a mangrove swamp. Mar Behav Physiol 16:209-223

Hazlett BA (1981) The behavioural ecology of hermit crabs. Annu Rev Ecol Syst 12:1-22

Hill MO, Gauch HG (1980) Detrended correspondence analysis, an improved ordination technique. Vegetatio 42:47-58

Kellogg CW (1976) Gastropod shells: a potentially limiting resource for hermit crabs. J Exp Mar Biol Ecol 22:101-111

MacGinite GE (1937) Notes on the natural history of several marine Crustacea. Am Midl Nat 18:1031-1037

McGuiness KA (1990) Physical variability, diversity gradients and the ecology of temperate and tropical reefs. Aust J Ecol 15:465-476

Nakasone Y (1988) Land hermit crabs from the Ryukyus, Japan, with a description of a new species from the 
Philippines (Crustacea, Decapoda, Coenobitidae). Zool Sci (Tokyo) 5:165-178

Pianka ER (1966) Latitudinal gradients in species diversity: a review of concepts. Am Nat 100:33-46

Rabaud E (1936) Le stéréotropisme des Pagures. CR Hebd Séances Acad Sci 202:350-352

Reay PJ, Haig J (1990) Coastal hermit crabs (Decapoda: Anomura) from Kenya, with a review and key to East African species. Bull Mar Sci 46:578-589

Rebach S (1974) Burying behaviour in relation to substrate and temperature in the hermit crab Pagurus longicarpus. Ecology 55:195-198

Reese ES (1969) Behavioural adaptations of intertidal hermit crabs. Am Zool 9:343-355

Editorial responsibility: Otto Kinne (Editor),

Oldendorf/Luhe, Germany
Turra A, Leite FPP (2000) Clustering behaviour of hermit crabs (Decapoda, Anomura) in an intertidal rocky shore at São Sebastião, Southeastern Brazil. Rev Bras Zool 60: $39-44$

Vance RR (1972) Competition and mechanisms of coexistence in three sympatric species of intertidal hermit crabs. Ecology 53:1062-1074

Vannini M (1975) Researches on the coast of Somalia. The shore and the dune of Sar Uanle. 5. Description and rhythmicity of digging behaviour in Coenobita rugosus Milne Edwards. Monit Zool Ital 6:233-242

Vannini M (1976) Field observations on the periodical transdunal migrations of the hermit crab, Coenobita rugosus Milne Edwards. Monit Zool Ital 7:145-195

Submitted: December 13, 2001; Accepted: April 23, 2002

Proofs received from author(s): July 22, 2002 